\title{
Earthquake numerical simulation of the dynamic and earthquake behaviour of Greek Post-Byzantine churches with and without base isolation
}

\author{
G. C. Manos \& N. Karamitsios \\ Lab. Strength of Materials and Structures, Dept. Civil Eng., \\ Aristotle University of Thessaloniki, Greece
}

\begin{abstract}
The dynamic and earthquake response of Post-Byzantine stone masonry churches, which were subjected to a damaging earthquake sequence in the region of Western Macedonia in Greece, is examined. One of these "Basilica" form churches is studied numerically; moreover, the study extends to the behavior of a two-story box-type church with a simple orthogonal vault and a wooden roof, which belongs to an 11th century monastic complex. These two structures are also studied together with the introduction of a base isolation system. The predicted performance of the various structural elements, located at the peripheral masonry walls, is then checked by applying an assumed MohrCoulomb failure envelope that is believed to represent the limit-state stonemasonry behavior. The numerical introduction of a base-isolation system was quite effective in lowering the demands and thus resulting for most structural elements in Capacity/Demand ratio values larger than one, which is assumed to indicate acceptable structural performance. However, the introduction of base isolation under an existing old stone-masonry structure is also faced with considerable difficulties, despite the favorable results of the numerical investigation. For "The Virgin Mary of Tourniki" these difficulties must be faced because this old church has to be moved to a different location due to flooding. Thus, introducing a base isolation scheme under this structure in its new location is a feasible solution for this particular case with no significant extra cost.
\end{abstract}

Keywords: Byzantine churches, stone masonry, dynamic response, earthquake performance, base isolation. 


\section{Introduction}

During the last thirty years various parts of Greece have been subjected to a number of damaging earthquakes ranging from $\mathrm{Ms}=5.2$ to $\mathrm{Ms}=7.2$ on the Richter scale. One of the most demanding tasks for counteracting the consequences of all these seismic events was the effort to ensure the structural integrity of old churches, that were built in periods ranging from 400 A.D. up to today; in many cases they sustained considerable damage (Manos et al. [1]). In what follows, selected results and summary observations are presented of the dynamic and seismic behavior of two structural systems that are utilized in a considerable number of churches belonging to the so-called Post-Byzantine period (16th to 19th century A.D.). The first structural system is of the form of a "Basilica" and it takes a number of variations in plan and height whereas the second type is a simple box-type structural formation. The present study examines the seismic behavior of one church belonging to the 1st structural system ("Typical PostByzantine Basilica"), representing at least five churches damaged by this earthquake sequence, and another church belonging to the 2nd structural system (Virgin Mary at Tourniki). All these churches are located in the region of Western Macedonia - Greece and they were all subjected to the damaging strong Kozani earthquake sequence of May, 1995. The numerical results presented here are part of an attempt to numerically explain the observed behavior. The numerical investigation includes modal analysis results; no attempt was made to compare these results with in-situ measurements for dynamic identification. Next, for all examined structures the numerical analysis predicts the demands imposed on the masonry structural elements by critical load combinations which include earthquake loading as specified by the Greek Seismic Code (ref. 2). Finally, the performance of the various masonry structural elements is evaluated in section 4 by examining the ratio values of the Capacity / Demand. The demands are obtained by assumed strength values, without the incorporation of any safety factors. Space limitations allow only very limited presentation of the observed actual damage. In general, the predicted damage regions agree well with observed damage. It is obvious that an important next step is the rehabilitation of the damaged masonry. The structural repairs of the stonemasonry churches examined here is inhibited by restrictions arising from retaining the visible stone-masonry architectural formations at the exterior and the frescos at the interior of the masonry walls. An acceptable type of repair is the application of low-pressure lime-mortar injections enriched with ceramic powder, resulting in a modest increase in the capacities of the various structural elements. The application of techniques used for the repair of reinforced concrete structural elements (jacketing or use of fiber rein-forcing plastics), utilizing the resulting considerable capacity increase, is not acceptable for the stone masonry of such cultural heritage structures. An alternative solution is lowering the demands by the use of base-isolation schemes as the ones investigated here. However, the introduction of base isolation under an existing old stone-masonry structure is also faced with considerable difficulties, despite the advantages that are shown by the results of numerical investigations as the one performed here. 


\subsection{The "Typical Post Byzantine Basilica"}

The first case is a three-nave Post Byzantine "Basilica" structural formation which, in the overall geometry, is typical of a number of churches with similar geometry which were damaged by a strong earthquake sequence in the region of Western Macedonia, Greece during the Kozani Earthquake of 1995. The overall dimensions of this "typical" case are $19 \mathrm{~m}$ length, $11 \mathrm{~m}$ width and $6.8 \mathrm{~m}$ height of the central nave (from ground level to the top of the roof). The internal colonnades are made of wood (figure 1).

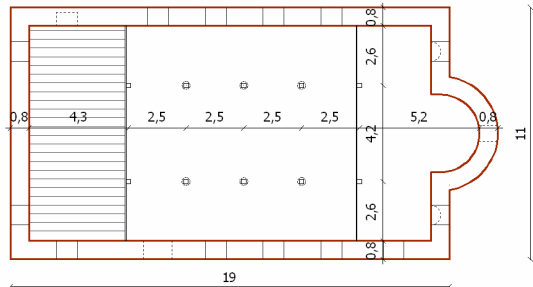

Plan

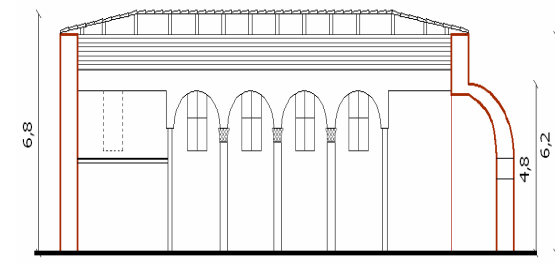

Cross Section

Figure 1: Typical Post-Byzantine "Basilica".

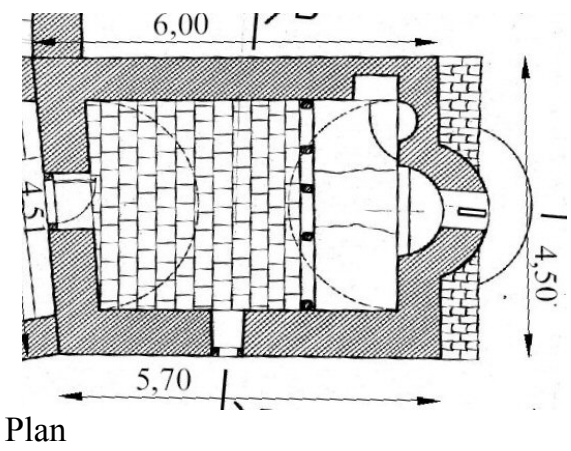

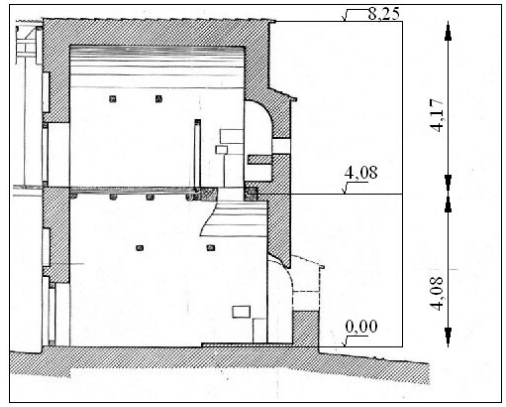

Cross section

Figure 2: Of Virgin Mary of the Monastic complex of Tourniki.

\subsection{The "Church of The Virgin Mary of Tourniki"}

This is a simple box-type structural system of rectangular shape, formed by the peripheral walls; a semi-cylindrical apse is part of the East wall for both the $1^{\text {st }}$ and the $2^{\text {nd }}$ story. This is the simplest formation of a "Basilica", that is of a single-space rectangular structure without interior separations. Such a structure is this two-story box-type Basilica, which is devoted to the Virgin Mary and belongs to the Monastic complex of Tourniki (Figure 3); it is a rather rare structural system that can be found in the monastic complexes of Mt. Athos. The behavior of this two-story Basilica is numerically simulated by focusing on the super-structure and in particular on the influence of the cylindrical vaulting 
system that exists at the 1st story level as well as at the roof. The numerical investigation for this 2 nd church is also extended to study the introduction of a base isolation system.

\subsubsection{Main features of the Church of the Virgin Mary of Tourniki}

The establishment of the monastic complex and the building of this church is set at the 11 th century A.D. This church is a two-story box-type "Basilica" structural system formed by two longitudinal walls (North and South) and two transverse walls (East and West) with a thickness of $700 \mathrm{~mm}$. The East transverse wall is dominated by two apses (one for each story) with a thickness of $700 \mathrm{~mm}$. A relatively complex system is constructed at the East transverse wall with the two Apses in order to transfer the gravitational forces of the top East wall and Apse, which are offset by $700 \mathrm{~mm}$ towards the interior of the church, when compared with the East wall and Apse of the bottom story (Figures 3). The top story ceiling is formed by a longitudinal semi-cylindrical vault with a thickness of $350 \mathrm{~mm}$ which supports the wooden roof together with the peripheral walls that extend appropriately for this purpose. Despite some small differences in the length of the North and South longitudinal walls, the structural system as a whole can be assumed to retain a mid-axis of symmetry with respect to the EastWest longitudinal direction. Apart from the difference in the length of the longitudinal walls the exact location of the window openings deviates from this symmetry; however, these deviations are not believed to be very significant. This church was also subjected to the same 1995 strong earthquake when the monastic complex was not in use; damage visible at the cylindrical vaults cannot be linked directly to this event.

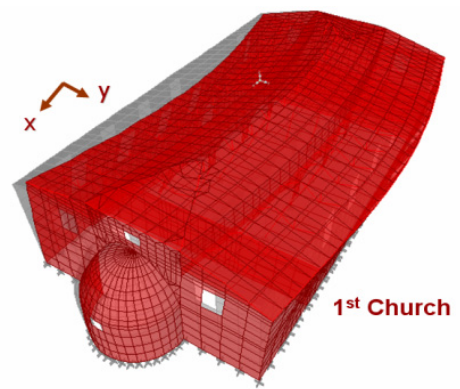

Translational y-y

Ty $=0.102$ sec., uy $=51.38 \%$

(Non-Isolated)

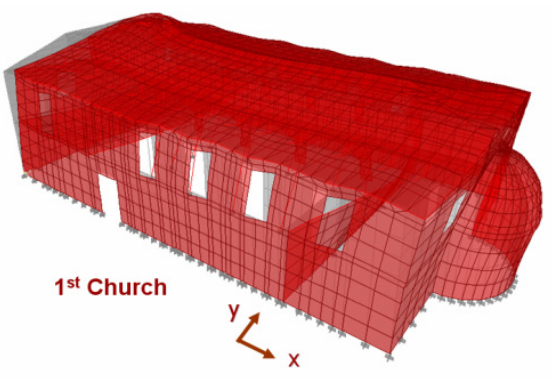

Translational $\mathrm{x}-\mathrm{x}$

$\mathrm{Tx}=0.069$ sec. $\mathrm{ux}=49,63 \%$

(Non-Isolated)

Figure 3: Dynamic characteristics "Typical Basilica".

\section{Modal analysis of the Post-Byzantine Basilicas}

A linear-elastic modal analysis was conducted assuming a value for the Young's Modulus for the masonry walls equal to 2500Mpa. The mass of these stone masonry walls was assumed to be equal to $2.70 \mathrm{t} / \mathrm{m}^{3}$. All the walls were 
numerically simulated by shell F.E. The arches on top of the internal colonnades as well as the wooden roof was also numerically simulated; the Young's Modulus of all the wooden parts was taken equal to $8400 \mathrm{Mpa}$ with the corresponding mass equal to $0.66 \mathrm{t} / \mathrm{m}^{3}$.

\subsection{The "Typical Post Byzantine Basilica"}

Figure 4 depicts the mainly horizontal translational eigen-modes for the 1 st structure. The translational eigen-mode in the transverse North-South (y-y) direction is the one with the longest eigen-period (Figure 4, $\mathrm{T}=0.102$ seconds). The structural response in this mode displaces the longitudinal peripheral walls mainly out-of-plane; this is done with the transverse peripheral walls resisting mainly in-plane. The translational eigen-mode in the longitudinal East-West ( $\mathrm{x}$ $\mathrm{x}$ ) direction is the next longest eigen-period (Figure $4, \mathrm{~T}=0.069$ seconds). The structural response in this mode displaces the longitudinal peripheral walls mainly in-plane; this is done with the transverse peripheral walls resisting mainly out-of-plane. Each one of these modes mobilizes approximately $50 \%$ of the total mass of the structure. These two modes are followed by higher order modes; however; these latter modes mobilize relatively small portions of the total mass.

\subsection{The "Church of The Virgin Mary of Tourniki"}

The first two horizontal translational mode shapes and eigen-periods are shown in figure 5. As can be seen, due to the two-story formation, these two eigenperiods are relatively longer than the corresponding values of the previously examined Typical Post-Byzantine Basilica. Moreover, these two eigen-modes also mobilize much larger modal mass ratios than the corresponding values of the previously examined Post-Byzantine Basilica, a fact that must be attributed to the box-type form of this structure; moreover, the peripheral masonry walls have relatively small dimensions to be excited in an out-of-plane manner.
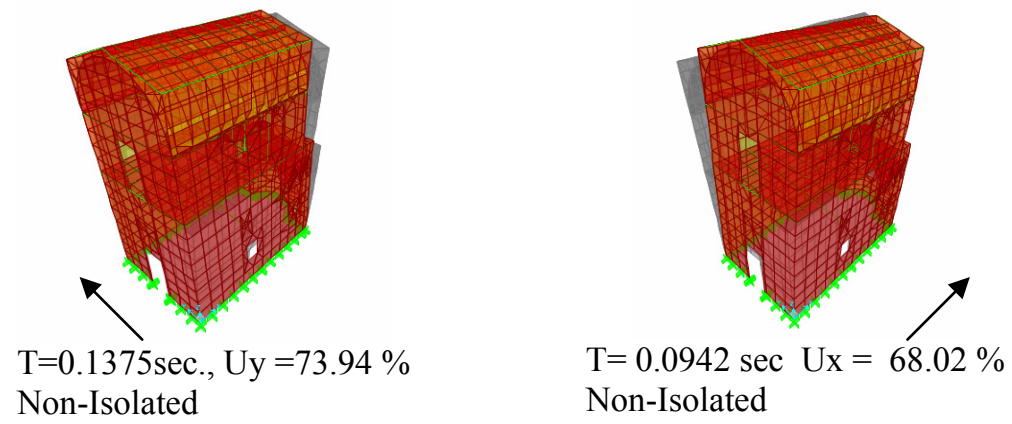

Figure 4: Dynamic characteristics of the "Church of the Virgin Mary of Tourniki”. 


\section{The demands from gravitational and earthquake loading}

The behavior of the selected structures was examined next when they were subjected to three distinct loading conditions. The forces in all these three loading conditions were applied in a static manner. The structures were assumed to have all three translational degrees of freedom (ux, uy, uz) restrained for all masonry at the foundation level. The first loading case included the dead (G) loads of all parts plus the live (Q) loads (mainly snow at the roof level plus the live load at the level used as women's quarters). During the second and third loading conditions the earthquake forces Ex and Ey were applied along the $\mathrm{x}-\mathrm{x}$ and the $y-y$ axis, respectively. This was done in a simple way assuming unit acceleration for all the parts of the structure equal to $1 \mathrm{~g}$ (where $\mathrm{g}$ is the acceleration of gravity). The dynamic nature of the seismic forces was taken into account in a separate series of simulations presented in the next section.

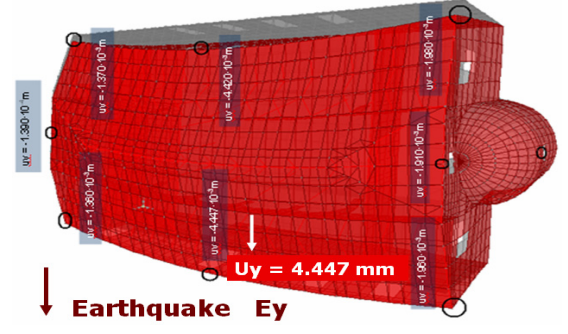

Figure 5: $\quad$ Deformations for Ey.

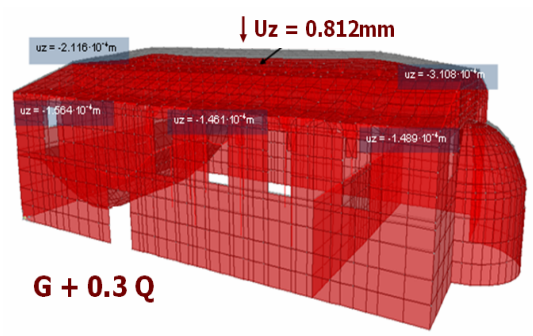

Figure 6: Deformations for gravity.

\subsection{The "Typical Post Byzantine Basilica"}

The results for the Post-Byzantine Basilica are depicted in figures 6a and 6b. As can be seen in these figures, this structural system is more flexible in the transverse than in the longitudinal direction. The resistance of the internal colonnades to either the $\mathrm{x}-\mathrm{x}$ or the $\mathrm{y}-\mathrm{y}$ seismic forces is very small as these structural elements are quite flexible. The maximum horizontal displacement at the roof level is equal to $1.94 \mathrm{~mm}$ for the 1 st church for the loading case Ex whereas it attains the value of $4.447 \mathrm{~mm}$ for the 1 st church for the loading case Ey, more than double than the $\mathrm{x}-\mathrm{x}$ maximum horizontal displacement. The seismic forces are mainly resisted by the in-plane action of the peripheral walls parallel to the direction of these forces as well as by the out-of-plane action of the peripheral walls normal to the direction of these forces. The maximum value of deformations from the gravitational forces is equal to $0.812 \mathrm{~mm}$ for the $1 \mathrm{st}$ church; this occurs along the vertical direction at mid-span of the top of the roof. The vertical deformations at the top of the peripheral walls are of the order of $0.1 \mathrm{~mm}$ to $0.2 \mathrm{~mm}$; moreover, the out-of-plane flexibility of the longitudinal walls results, at their top, in out-of-plane deformations of the order of $0.15 \mathrm{~mm}$ when the structure is subjected to the gravitational forces. 


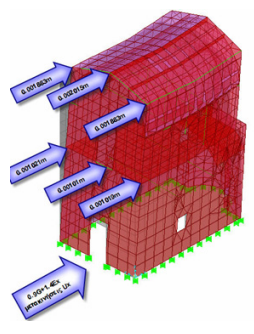

Non-Isolated

$0.9 \mathrm{G}+1.4 \mathrm{Ex}$

$\delta \mathrm{xmax}=$

$2.015 \mathrm{~mm}$

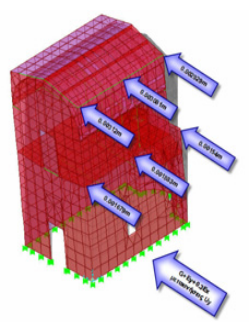

Non-Isolated

$0.9 \mathrm{G}+1.4 \mathrm{Ey}$

dymax $=$

$3.081 \mathrm{~mm}$

Figure 7: Displacements of the "Church of the Virgin Mary of Tourniki".

\subsection{The "Church of The Virgin Mary of Tourniki"}

The small size in plan for this church and the box-type formation results in relatively small horizontal displacement amplitudes at the roof level for the combination of gravity loads and seismic forces along the $x-x$ and the $y-y$ direction as depicted in figure 7. The maximum value of the horizontal displacements at this level is approximately $3.1 \mathrm{~mm}$ and develops, as expected, along the direction with the relatively smaller stiffness (North-South, y-y). This structural formation is designated in this figure as non-isolated to differentiate it with the same structure being isolated, as will be presented in section 5 .

\section{Evaluation of the stress results}

This time the design spectrum of the Greek Seismic Code (Greek Seismic Code 2000 , ref. 2) was utilized for seismic zone I (ground design acceleration $0.16 \mathrm{~g}$ ), soil category $\mathrm{B}$, response modification factor $\mathrm{q}=1.5$ and importance factor 1.3. In the spectral dynamic analyses that were conducted, the resultant seismic forces were obtained from the Greek Seismic Code response spectrum and the following loading combinations ( $\mathrm{G}$ the dead loads, Ex and Ey the earthquake action in the $\mathrm{x}$ and $\mathrm{y}$ directions). $0.9 \mathrm{G}+1.4 \mathrm{Ey} / 0.9 \mathrm{G}+1.4 \mathrm{Ex} / \mathrm{G}+\mathrm{Ey}+0.3 \mathrm{Ex} /$ $\mathrm{G}+\mathrm{Ex}+0.3 \mathrm{Ey}$. From all the load combinations, the most critical in-plane demand values, either in normal or shear stresses, can be identified for all four peripheral walls. This can also be done for the most critical out-of-plane normal stress demand values for all four peripheral walls. Next, certain commonly used masonry failure criteria were adopted for either in-plane tension-compression or shear or out-of-plane tension.

Table 1 lists values which were assumed to be valid for the critical mechanical properties for the masonry segments (refs. [1] and [3]). Moreover, a Mohr-Coulomb failure envelope was adopted for the in-plane shear limit state of the stone masonry, when a $\sigma_{\mathrm{n}}$ normal stress is acting simultaneously, that is defined through the relationship:

$$
\mathrm{f}_{\mathrm{vk}}=\mathrm{f}_{\mathrm{vko}}+0.4 \sigma_{\mathrm{n}}
$$

where: $\mathrm{f}_{\mathrm{vko}}$ is the shear strength of the stone masonry when the normal stress is zero; $f_{\mathrm{vko}}$ was assumed to be equal to $0.192 \mathrm{~N} / \mathrm{mm}^{2}$. 
All the masonry parts of the three studied structures were examined in terms of in-plane and out-of-plane stress demands posed by the considered load combinations against the corresponding capacities, as these capacities were obtained by applying the Mohr-Coulomb criterion of equation (1) or the upper stone masonry compressive and tensile strength limits listed in Table 1.

Due to space limitations such results are not shown in detail here. Selective results obtained from this evaluation process are shown in figures 8 and 9 for the two studied churches, respectively. With $\mathrm{R} \sigma$ or with $\mathrm{R} \tau$ the ratio of the in-plane tensile or shear strength value over the corresponding demand is signified whereas with $R_{M}$ the ratio of the out-of-plane tensile strength value over the

Table 1: $\quad$ Assumed mechanical characteristics of the Stone Masonry.

\begin{tabular}{|c|c|c|c|}
\cline { 2 - 4 } \multicolumn{1}{c|}{} & $\begin{array}{c}\text { Stone Masonry } \\
\text { Compressive } \\
\text { Strength }\left(\mathrm{N} / \mathrm{mm}^{2}\right)\end{array}$ & $\begin{array}{c}\text { Stone Masonry } \\
\text { Tensile Strength } \\
\left(\mathrm{N} / \mathrm{mm}^{2}\right)\end{array}$ & $\begin{array}{c}\text { Shear Strength } \\
\mathrm{f}_{\mathrm{vko}} \\
\left(\mathrm{N} / \mathrm{mm}^{2}\right)\end{array}$ \\
\hline Upper limit & 3.846 & 0.250 & 0.192 \\
\hline Lower limit & 1.00 & 0.192 & 0.192 \\
\hline
\end{tabular}

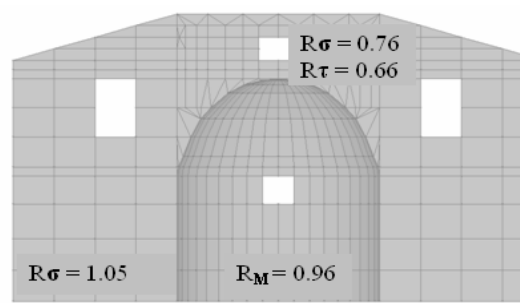

East wall

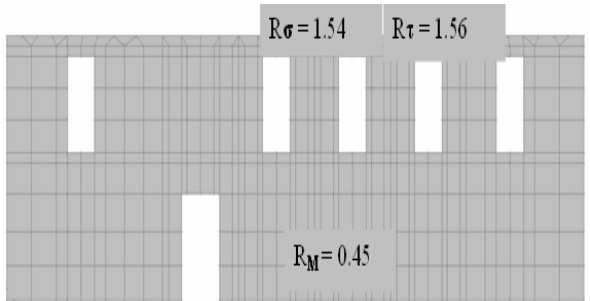

South wall

Figure 8: "Typical Post Byzantine Basilica" ratio values of strength over demands.

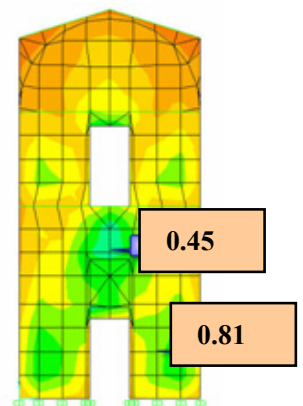

Shear stress Capacity / demand R $\tau$ Non-Isolated $0.9 \mathrm{G}+1.4 \mathrm{Ey}$

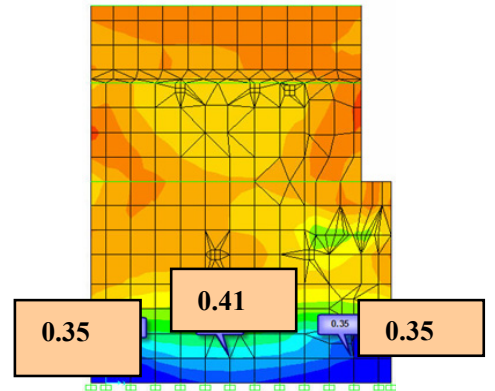

Normal stress Capacity / demand R $\sigma$ Non-Isolated $0.9 \mathrm{G}+1.4 \mathrm{Ex}$

Figure 9: The "Church of The Virgin Mary of Tourniki". 
corresponding demand is denoted. Ratio values smaller than 1.0 predict a corresponding limit-state condition leading to damage. As can be seen from the capacity over demand ratio values presented in figures 8 and 9 there are regions on the masonry walls that these ratio values are well below 1, indicating damage. All these predicted zones of potential failure are credible, as can be deduced from such damage patterns observed in the three studied structural systems after the 1995 strong earthquake event.

\section{Structural performance introducing a base isolation}

A base isolation system was next introduced in the studied structures representing the "Typical Post Byzantine Basilica", as indicated in figure 10a as well as at the "Church of The Virgin Mary of Tourniki" as indicated in figure 10b). In figure 11 the design spectrum considered for the non-isolated (fixed) and the isolated structural systems is shown together with the corresponding fundamental eigen-periods of the non-isolated (fixed) and the isolated structural systems. As can be seen in this figure, the dynamic amplification for the non-isolated and the isolated structures is approximately of the same order. This is due to the fact that for seismic isolated structures the response modification factor takes the value of $\mathrm{q}=1$ instead of $\mathrm{q}=1.5$ that was used for un-reinforced masonry structures. The possibility to use more flexible base isolation schemes is currently investigated.

In figures 12 and 13 the deformation demands at the isolation level are depicted for the "Typical Post Byzantine Basilica" and the "Church of The Virgin Mary of Tourniki", respectively. As can be seen they are of the order of $145 \mathrm{~mm}$ maximum for the first structural system and only $163 \mathrm{~mm}$ for the second structural system. What is of the outmost interest, apart from the deformation demands of the base isolation devices, is the effect the introduced base isolation scheme had on the values of the capacity / demand ratio, which were used in the section 4 before to predict numerically the observed earthquake structural damage for these churches. This is presented in the following section by comparing these ratio values for the non-isolated structure with the corresponding values of the isolated structure.

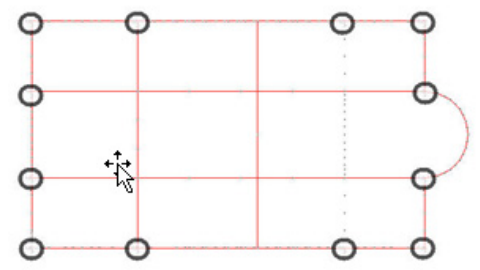

a) The "Typical Basilica"

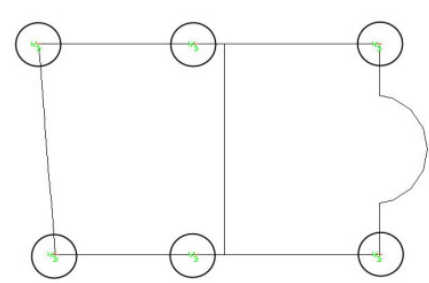

b) Church at Tourniki

Figure 10: Arrangement of the base isolation scheme. 


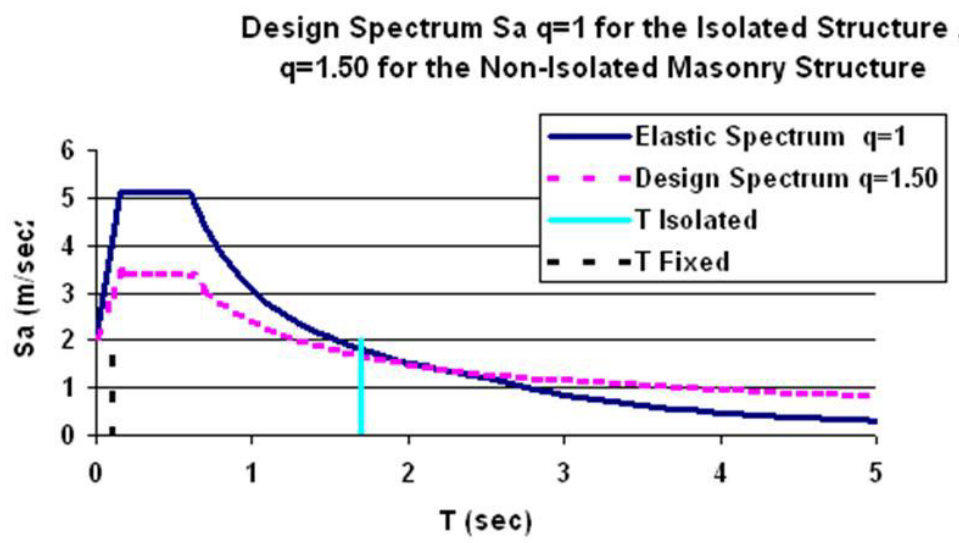

Figure 11: Design spectrum used in the numerical simulations.

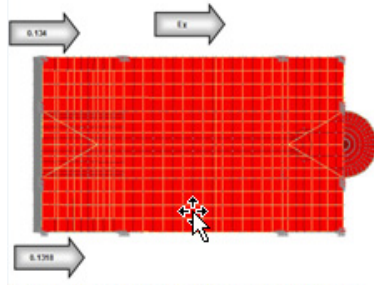

EQ Ex Max. displ. $=0.134 \mathrm{~m}$ at the Isolator level

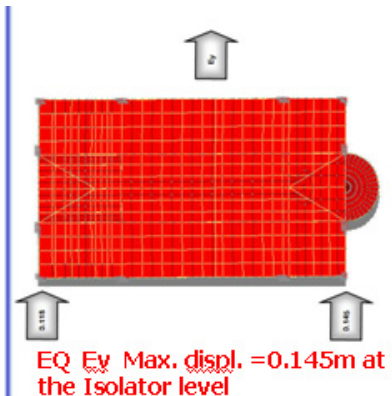

the Isolator level

Figure 12: Horizontal displacement of base isolated "Typical Post Byzantine Basilica".

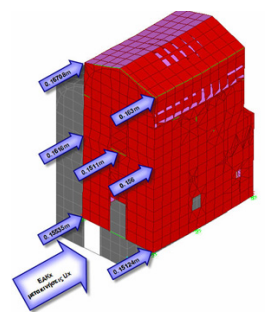

$$
\begin{gathered}
0.9 \mathrm{G}+1.4 \mathrm{Ex} \\
\text { Top } \\
\delta \mathrm{xmax}= \\
167.08 \mathrm{~mm} \\
\text { Base } \\
\delta \mathrm{xmax}= \\
156.35 \mathrm{~mm}
\end{gathered}
$$

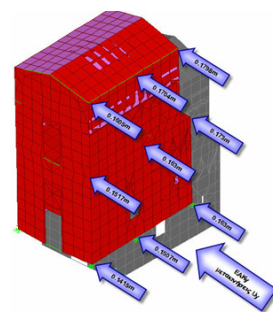

$$
\begin{gathered}
0.9 \mathrm{G}+1.4 \mathrm{Ey} \\
\text { Top } \\
\delta \mathrm{ymax}= \\
179.8 \mathrm{~mm} \\
\text { Base } \\
\delta \mathrm{ymax}= \\
163.0 \mathrm{~mm}
\end{gathered}
$$

Figure 13: Horizontal displacement of base isolated base "Church of The Virgin Mary of Tourniki”.

\subsection{The predicted capacity/demand performance of the isolated structures}

In this section, the results that were obtained for the isolated structures are processed in the same way as presented in section 4 by applying the same failure 
criteria that were employed for the non-isolated structures. The results of this evaluation must be viewed with the consideration that there is no reduction in the earthquake loads of the isolated structures, due to the moderate flexibility of the used isolation schemes and the employed design spectrum of figure 11 combined with the response modification factor value $\mathrm{q}=1.0$ for the isolated structure, as already mentioned. Such a reduction of the earthquake loads will result from the use of a more flexible base isolation scheme than the one employed here.

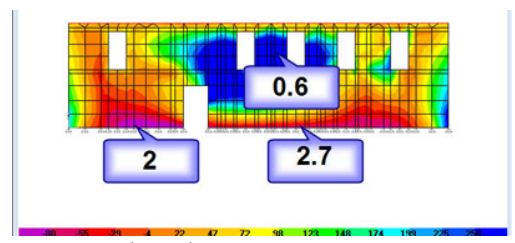

Non-Isolated

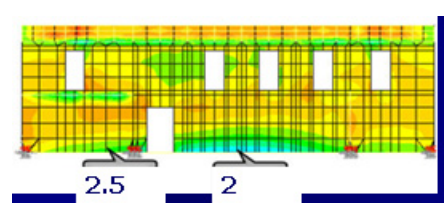

Isolated

Figure 14: South wall (outside face) $0.9 \mathrm{G}+1.4$ Ey, Out-of-plane S22 strength / demand ratio, "Typical Post Byzantine Basilica".

\subsubsection{The "Typical Post Byzantine Basilica"}

In figure 14 the strength over demand ratio values for the "Typical Post Byzantine Basilica" structural system are shown for both the non-isolated as well as the isolated case. These selected results for the non-isolated structure correspond to ratio values well smaller than 1 , which as explained in section 4 represents structural damage, As can be seen, for the case of the isolated structure the corresponding strength over demand ratio values at the same locations are well above 1 , which indicates that with the introduction of the base isolation scheme structural damage from earthquake loads should be minimized.

\subsection{2 "The Church of the Virgin Mary of Tourniki"}

In figure 15 the strength over demand ratio values for the "Virgin Mary of Tourniki" are shown for both the non-isolated and the isolated case. The selected results for the non-isolated structure correspond to ratio values well smaller than 1 , which, as explained in section 4 , represents structural damage. As was the case before, the corresponding strength over demand ratio values at the same locations are well above 1 in almost all cases for the isolated structure. Thus, as expected, structural damage from earthquake loads should be minimized with a base isolation scheme. This improvement in the expected earthquake performance of the studied structural systems will become even better if a more flexible isolation scheme than the one employed here is used.

Obviously, the increased flexibility of the base isolation scheme will result in larger deformation demands of the base isolation devices than the ones predicted here (figures 12 and 13); the selected devices must then pass such relevant checks.

At this point it is important to stress the following difficulties in applying a base isolation scheme on an existing structural system especially in the case that the structural system is un-reinforced masonry, as is the case of both structural 


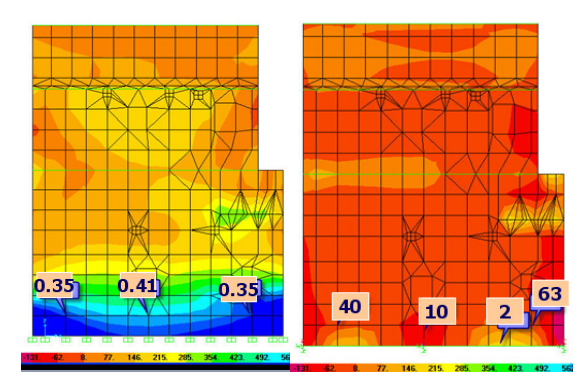

Non-Isolated

Isolated

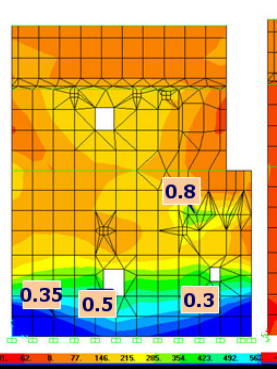

Non-Isolated

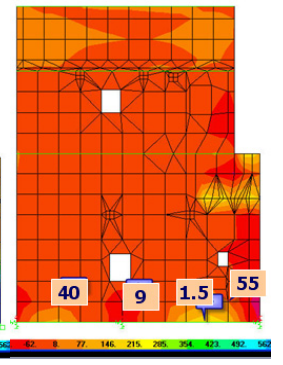

Isolated

Normal stress Strength / Demand ratio Ro, Loading G+Ey

Figure 15: The Church of The Virgin Mary of Tourniki.

systems that were investigated here. In order to place the base isolation devices under the existing structure a system of additional foundation must be constructed under the masonry walls that will enable such an operation. Such systems have been tried in the past; however, apart from the difficulty in construction this additional foundation one should also consider the extra cost. Another difficulty is the fact that many times below the existing churches lie older structures; thus the excavation for constructing the additional foundation will unveil such old remains. This is not the case for the structures that were investigated here. On the contrary, "The Church of The Virgin Mary of Tourniki" has to be moved in a different location due to the flooding of the current location, where it was constructed almost eight hundred (800) years ago, from the construction of a dam that already starts filling the valley. In this case, the operation of construction an additional foundation for lifting and sliding this church cannot be avoided. The authors of this pa-per argue in favor of the placement of a base isolation scheme under this structure in its new location is a feasible solution for this particular case with no significant extra cost. Obviously, thus base isolation scheme should be considered in addition to all other traditional repair and strengthening measures for this church.

\section{Conclusions}

1. The numerical results presented here are part of an attempt to numerically explain the observed seismic behavior of Post-Byzantine stone masonry churches. The relatively simplified linear analysis approach together with the adopted failure criteria seems to verify the development of the actual damage in all three examined structural formations. Both predicted and actual damage is mainly concentrated at the keys and supports of the arches and vaults, at the supports of the roofing system as well as at the door and window openings and the bases of the peripheral walls. Further extensive verification is needed for the assumed strength values utilized by the failure criteria. A number of tests are currently under way. 
2. The numerical introduction of a base-isolation system for the third structural formation, was quite effective in lowering the demands and thus resulting for most structural elements in Capacity/Demand ratio values larger than one (Capacity/Demand $>1$ ), which is assumed to indicate acceptable structural performance. However, the introduction of base isolation under an existing old stone-masonry structure is also faced with considerable difficulties, despite the advantages that are shown by the results of numerical investigation.

3. In the particular case of "The Church of The Virgin Mary of Tourniki" these difficulties must be faced because this old church has to be moved to a different location due to flooding. Thus, the placement of a base isolation scheme under this structure in its new location is a feasible solution for this particular case with no significant extra cost. Obviously, this base isolation scheme should be considered in addition to all other traditional repair and strengthening measures for this church.

\section{References}

[1] Manos G.C., Soulis V., Diagouma A. (2008) "Numerical Investigation of the behavior of the church of Agia Triada, Drakotrypa, Greece", Journal in Advances in Engineering Software 39 (2008) 284-300.

[2] Provisions of Greek Seismic Code 2000 , OASP, Athens, December 1999.

[3] European Committee for Standardization, Euro code 6; "Design of Masonry Structures, Part 1-1:General Rules for Building. Rules for Reinforced and Un-reinforced Masonry”, EN 1996-1-1:2005. 